\title{
Review
}

\section{Proton Therapy for Prostate Cancer: Challenges and Opportunities}

\author{
Darren M. C. Poon $\left.{ }^{1}{ }^{(}\right)$, Stephen $\mathrm{Wu}^{2, *}$, Leon $\mathrm{Ho}^{2}$, Kin Yin Cheung ${ }^{2}$ and Ben $\mathrm{Yu}^{2}$ \\ 1 Comprehensive Oncology Centre, Hong Kong Sanatorium \& Hospital, Hong Kong 999077, China; \\ mc_poon@clo.cuhk.edu.hk \\ 2 Medical Physics Department, Hong Kong Sanatorium \& Hospital, Hong Kong 999077, China; \\ leon.cc.ho@hksh.com (L.H.); kycheung@hksh.com (K.Y.C.); benyu@hksh.com (B.Y.) \\ * Correspondence: stephen.th.wu@hksh.com; Tel.: +852-29171413
}

check for updates

Citation: Poon, D.M.C.; Wu, S.; Ho, L.; Cheung, K.Y.; Yu, B. Proton Therapy for Prostate Cancer: Challenges and Opportunities. Cancers 2022, 14, 925. https:// doi.org/10.3390/cancers14040925

Academic Editors: Erik W. Korevaar and Arjen van der Schaaf

Received: 20 December 2021

Accepted: 11 February 2022

Published: 13 February 2022

Publisher's Note: MDPI stays neutral with regard to jurisdictional claims in published maps and institutional affiliations.

Copyright: (c) 2022 by the authors. Licensee MDPI, Basel, Switzerland. This article is an open access article distributed under the terms and conditions of the Creative Commons Attribution (CC BY) license (https:// creativecommons.org/licenses/by/ $4.0 /)$.
Simple Summary: Reported clinical outcomes of proton therapy (PT) for localized prostate cancer are similar to photon-based external beam radiotherapy. Apparently, the dosimetric advantages of PT have yet to be translated to clinical benefits. The suboptimal clinical outcomes of PT might be attributable to inadequate dose prescription, as indicated by the ASCENDE-RT trial. Moreover, uncertainties involved in the treatment planning and delivery processes, as well as technological limitations in PT treatment systems, may lead to discrepancies between planned doses and actual doses delivered to patients. In this article, we reviewed the current status of PT for prostate cancer and discussed different clinical implementations that could potentially improve the clinical outcome of PT for prostate cancer. Various technological advancements under which uncertainties in dose calculations can be minimized, including MRI-guided PT, dual-energy photon-counting CT and high-resolution Monte Carlo-based treatment planning systems, are highlighted.

\begin{abstract}
The dosimetric advantages of proton therapy (PT) treatment plans are demonstrably superior to photon-based external beam radiotherapy (EBRT) for localized prostate cancer, but the reported clinical outcomes are similar. This may be due to inadequate dose prescription, especially in high-risk disease, as indicated by the ASCENDE-RT trial. Alternatively, the lack of clinical benefits with PT may be attributable to improper dose delivery, mainly due to geometric and dosimetric uncertainties during treatment planning, as well as delivery procedures that compromise the dose conformity of treatments. Advanced high-precision PT technologies, and treatment planning and beam delivery techniques are being developed to address these uncertainties. For instance, external magnetic resonance imaging (MRI)-guided patient setup rooms are being developed to improve the accuracy of patient positioning for treatment. In-room MRI-guided patient positioning systems are also being investigated to improve the geometric accuracy of PT. Soon, high-dose rate beam delivery systems will shorten beam delivery time to within one breath hold, minimizing the effects of organ motion and patient movements. Dual-energy photon-counting computed tomography and highresolution Monte Carlo-based treatment planning systems are available to minimize uncertainties in dose planning calculations. Advanced in-room treatment verification tools such as prompt gamma detector systems will be used to verify the depth of PT. Clinical implementation of these new technologies is expected to improve the accuracy and dose conformity of PT in the treatment of localized prostate cancers, and lead to better clinical outcomes. Improvement in dose conformity may also facilitate dose escalation, improving local control and implementation of hypofractionation treatment schemes to improve patient throughput and make PT more cost effective.
\end{abstract}

Keywords: prostate; proton therapy; magnetic resonance imaging

\section{Introduction}

Proton therapy (PT) was first proposed by Robert R Wilson in 1946 [1] because of the unique dosimetric property of proton beams known as the Bragg peak. In theory, a proton beam traversing a medium deposits a relatively small amount of radiation before it reaches 
the Bragg peak, and no radiation beyond it. The depth of the Bragg peak in the medium is determined by the energy of the protons. By irradiating the medium with proton beams of different energies, a range of spread-out Bragg peaks (SOBPs) can be positioned at a pre-defined depth of the medium, as determined by the range of the beam energies. PT takes advantage of this dosimetric property to deliver a conformal therapeutic dose of radiation to the patient by positioning the SOBP of a proton beam, of appropriate field size and range of beam energies, to precisely cover the tumor volume without damaging the normal surrounding tissue. Treatment planning studies have demonstrated superior dosimetric benefits of PT plans compared with plans for conventional external beam radiotherapy (EBRT), such as intensity-modulated radiotherapy (IMRT) and volumetric modulated RapidArc therapy (VMAT) [2,3].

Treatment of patients with PT began around 1954 [4], but progress in the development of this modality has been slow due to numerous technical hurdles. Challenges for PT pioneers included the immaturity of the PT accelerator and dose-delivery systems in handling complex treatments, lack of knowledge on dosimetric properties such as the relative biological effectiveness (RBE) of proton beams, and lack of interest and incentive in the manufacturing industry to invest in developments of PT equipment [5]. This situation changed when the US Food and Drug Administration approved the clinical use of PT in 1988 [6], and the world's first hospital-based PT system was established, at Loma Linda University Medical Center in California, in 1990. Since then, the number of hospital-based PT facilities has increased exponentially, with 104 PT treatment facilities operating globally by the end of 2021 and many more under construction and planning [7]. By the end of 2020, over 250,000 patients had been treated with PT worldwide [7]. Although prostate cancer has been one of the main treatment sites in PT, the practice has been controversial because of a lack of clinical evidence to justify the treatment cost [8]. Reported clinical outcomes in both local control and toxicity of PT for prostate cancer are similar to those for EBRT. The theoretical dosimetric benefits of PT have not translated to greater clinical benefits than EBRT for the prostate, as they have in other diseases sites, including pediatric malignancies of the central nervous system, large liver cancers, ocular melanomas, chordomas and chondrosarcomas $[9,10]$. The far-below-expected performance of PT in treatment outcomes in prostate cancer has been attributed to two main causes. First, the results of the randomized controlled Androgen Suppression Combined with Elective Nodal and Dose Escalated Radiation Therapy (ASCENDE-RT) trial [11] point to inadequate dose prescription, particularly in patients with high-risk disease, indicative of a dose-response characteristic of radiotherapy (RT) of the prostate. Second, improper dose delivery due to large uncertainties associated with the individual processes involved in PT and pre-treatment workflow may compromise the dose conformity of PT treatment, as demonstrated by robust planning [12]. The objectives of this review are twofold: (1) examine the underlying reasons behind the disappointing clinical outcomes in PT treatment of prostate cancer; and (2) investigate new PT technologies and innovative work procedures that are being implemented, how they may improve the accuracy and quality of PT treatment and facilitate a reduction in treatment margins, and the possibility of dose escalation to the appropriate level.

\section{Potential Benefits of PT and Reported Clinical Outcomes of Prostate Treatments}

Given the different beam characteristics of protons and photons, a modulated proton beam confines dose deposition to the target region, with a rapid depth- and lateral-dose fall-off favoring normal tissue sparing and target dose escalation. Several dose-volume comparison studies showed that both passive scattering $[13,14]$ and pencil beam scanning [2,15] PT reduced the mean dose and percentage of volume receiving low dose in the rectum and bladder compared with IMRT. In the prostate, PT maintained dose coverage, demonstrating superior dose conformity over IMRT. In most circumstances, a simple bilateral proton beam is employed for localized prostate cancer. Other arrangements, such as anterior-posterior or anterior-oblique beams may be used in patients with a hip prosthesis or previously irradiated hip [16-18]. Nevertheless, PT has consistently been shown to have 
a smaller irradiated volume of normal tissue and lower integral non-target dose [14,15], as illustrated in Figure 1. A systematic review showed that the risk of radiation-induced second primary cancer appears to be small (range, 1 in 290 to 1 in 220 over all durations of follow-up), but does increase over time [19]. As prostate cancer survival improves, the risk of radiation-induced second malignancies becomes more relevant [20].

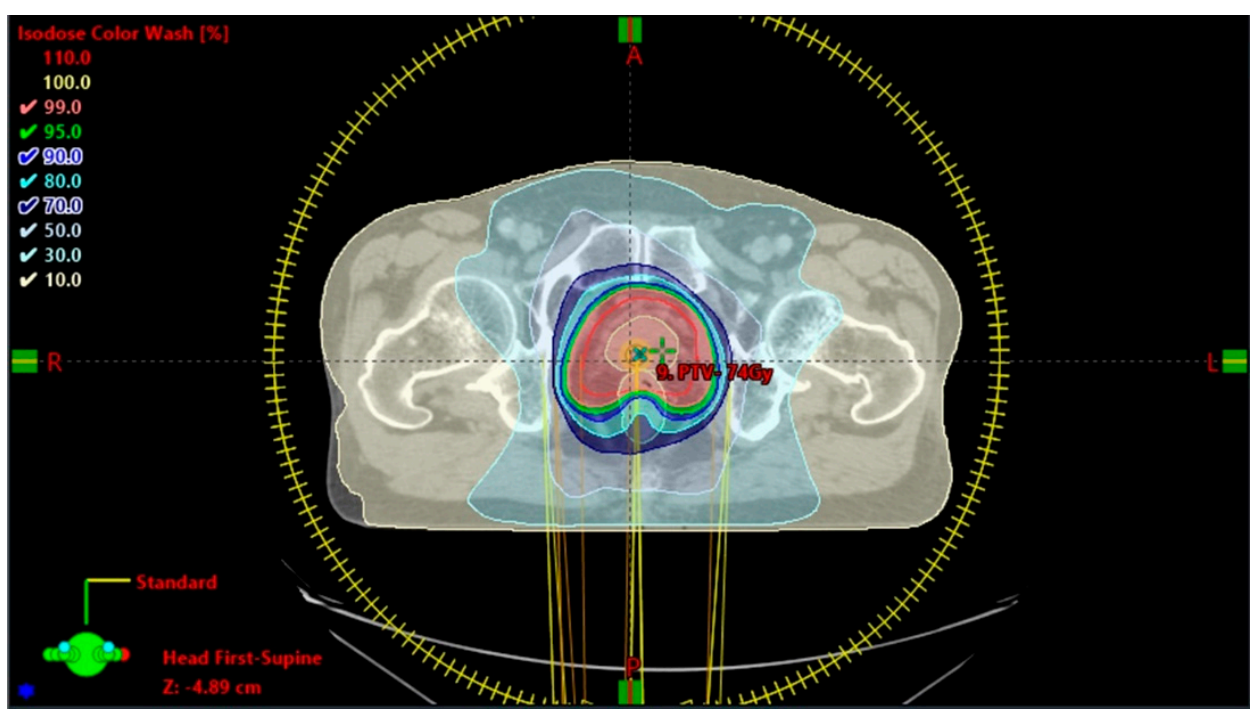

(A)

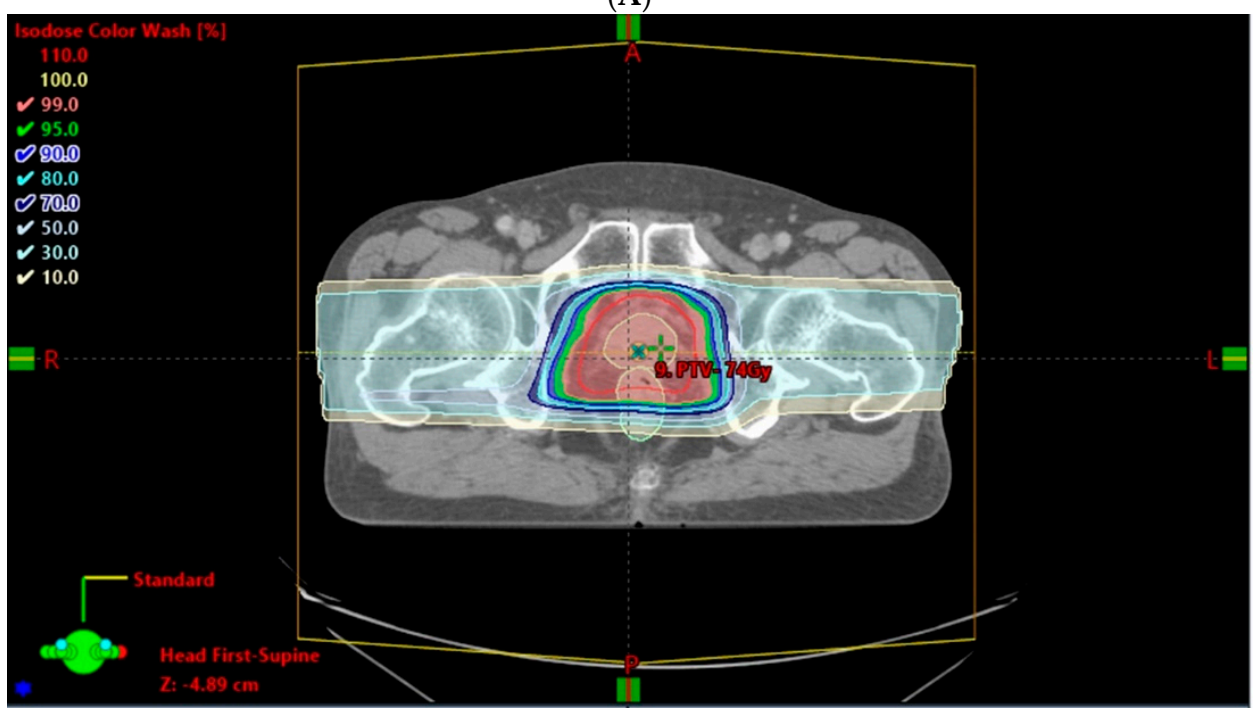

(B)

Figure 1. Integral dose comparison of volumetric modulated RapidArc therapy (VMAT)-full rotation (A) and photon therapy (PT)-bilateral (B) in prostate treatment plans. The most significant differences were in the $10 \%$ and $30 \%$ isodose distributions of the $78-\mathrm{Gy}$ prescription.

There is diverging evidence regarding the superiority of PT over IMRT in terms of disease control, survival and toxicity. A retrospective study at Loma Linda University reported overall 5- and 8-year actuarial biochemical disease-free survival rates of 75\% and 73\%, respectively, for PT in localized prostate cancer [21]. Another study compared the 5-year biochemical recurrence-free survival (bRFS) rates for intermediate-risk prostate cancer patients after surgical intervention and RT, which were $85.7 \%$ and $89.5 \%$ in patients treated with EBRT and permanent seed implant, respectively [22]. A randomized trial showed a similar biochemical failure rate for localized prostate cancer treated with highdose PT and permanent brachytherapy [23]. Recently, a single-center retrospective study in Japan showed that 5- and 10-year freedom-from-biochemical-relapse rates were 93\% and 
$86 \%$, respectively, for intermediate-risk prostate cancer patients receiving 74 Gy (RBE) in 37 fractions of PT [24]. Apart from disease control and survival, several patient-reported prospective studies compared genitourinary (GU) and gastrointestinal (GI) toxicity, as well as sexual domain issues, between photon- and proton-based treatments [25-27]. Two studies, with follow-up duration up to 2 years, reported no differences in the GU, GI or sexual quality of life (QoL) scores [25,26]. Massachusetts General Hospital reported improvement in bowel QoL at 2-3 months after PT, but worsened urinary QoL at 1 year after PT. At the 2-year follow-up, however, there were no differences in either bowel/rectal QoL or urinary QoL between photon- and proton-based treatments [25]. Other claim-based studies showed degraded GI QoL $[8,28,29]$. Currently there are limited randomized trial data with which to evaluate the efficacy of proton- versus photon-based treatments, and various single-center/institute studies have reported mixed data. Therefore, a consensus has yet to be reached.

The theoretical dosimetric advantages of PT have not borne fruit clinically. Dose prescription might be a factor in the suboptimal clinical outcomes of PT. Numerous randomized trials have compared various dose prescriptions (range, 64 to $86.4 \mathrm{~Gy}$ ) of 3D-conformal RT or IMRT, in which higher dose prescription demonstrated superior biochemical tumor control and decreased the risk of distant metastases for prostate cancer in different risk groups [30-36]. In the ASCENDE-RT trial, the low-dose rate brachytherapy (LDR-PB) boost arm received an iodine-125 implant prescribed at the minimum peripheral dose of $115 \mathrm{~Gy}$, while the dose-escalation external beam (DE-EBRT) boost arm received an additional 32 Gy (total, $78 \mathrm{~Gy}$ ) in 16 fractions. The LDR-PB boost patients were twice as likely to be free of biochemical failure at a median follow-up of 6.5 years [37]. Recalling the two largest single-center studies, a PT dose of 74 Gy, which lies in the middle of the dose-prescription spectrum, was employed. The authors speculated that there was room for escalating the dose prescription with PT, provided that the dose was delivered precisely and accurately.

Another factor limiting the potential of PT could be discrepancies between planned doses and actual doses delivered to patients. Major contributors to such discrepancies include uncertainties involved in the treatment planning and delivery processes, as well as technological limitations in PT treatment systems. Proton beams manifest an intrinsic range uncertainty due to range straggling, in which the absolute straggling width increases with energy. Water equivalent thickness is a one-dimensional range estimate in a heterogeneous medium. Monte Carlo (MC)-based studies have demonstrated that not only is the range related to water equivalent thickness, but it is also sensitive to the geometry and position of tissue density variation relative to the depth of the Bragg peak [38-43]. A study analyzed the inter-fraction motion of prostate cases with daily volumetric megavoltage X-ray computed tomography (CT). It showed that the higher uncertainties for inter-fraction range changes in lateral beams compared to anterior beams are likely due to the relative positions of the femoral head and the prostate between fractions of PT [44]. Range uncertainty can also be related to stopping power ratio (SPR) conversion. SPR is commonly converted from the Hounsfield unit (HU) in CT images using a generic look-up table. Studies have analyzed the uncertainties from various sources, including CT image noise [45], artifacts [46,47], tissue composition variation [48-51], and others. A notable study by Yang et al. reported that the 95th percentile of composite range uncertainty in the prostate region is 3\% [48]. Apart from range uncertainty, setup error and inter-/intra-fraction organ motion also played important roles in dose delivery accuracy because of the steep dose gradient in PT. A study by Park et al. [52] compared dose variations upon the introduction of various systematic and random setup errors (Gaussian distribution with standard deviation of $2 \mathrm{~mm}$ ) in proton clinical plans for prostate cancer. Although the target coverage in the prostate was retained $\left(-0.3 \%\right.$ to nominal plan), the standard deviation of $V_{45 G y}$ for the rectum was $5.6 \%$, suggesting that noticeable deviations from the nominal plan may result from setup errors [52].

The RBE of PT has typically been taken as a spatially invariant value of 1.1, regardless of clinical endpoint [38]. However, dose- and depth-dependence of RBE has been demon- 
strated in which the RBE values in the distal edge rose to 1.21 [53,54]. A wide RBE range was reported in low $\alpha / \beta$ biological systems, with RBE values often above 1.1 within the SOBP linear energy transfer (LET) range, compared with the lower RBE values of high $\alpha / \beta$ systems (below 1.1). Dose per fraction was also reported to have an impact on RBE for low $\alpha / \beta$ biological systems [55]. Based on existing in vitro and in vivo studies, the RBE uncertainty in normal tissue is higher (compared to the nominal value of 1.1), potentially causing unexpected complications and toxicity.

\section{Opportunities for Improvement with New Technologies and Innovative Techniques}

For decades, PT treatment systems with double scattering or a wobbling beam with brass aperture collimation and compensator have been used to treat prostate cancer. Large treatment margins of up to $10 \mathrm{~mm}$ or more were used in "large field" conventional PT techniques [50,56], and contributed to critical organ toxicity [57]. Most of the reported clinical data were based on treatments delivered with this large field technique. With the recent commercial availability of the latest generation of PT technologies, clinical implementation of new techniques such as intensity modulated proton therapy (IMPT) can now be realized. IMPT is capable of delivering treatment with superior dose conformity, which can potentially provide better protection of critical organs, as illustrated by the dose displays of two treatment plans shown in Figure 2. In principle, a reduction in the regions of critical organs that are exposed to high radiation doses will help reduce related toxicity [15]. In reality, dose conformity of IMPT treatment plans may not always be reproducible in a patient's course of treatment because of the various uncertainties involved in treatment and pre-treatment processes.

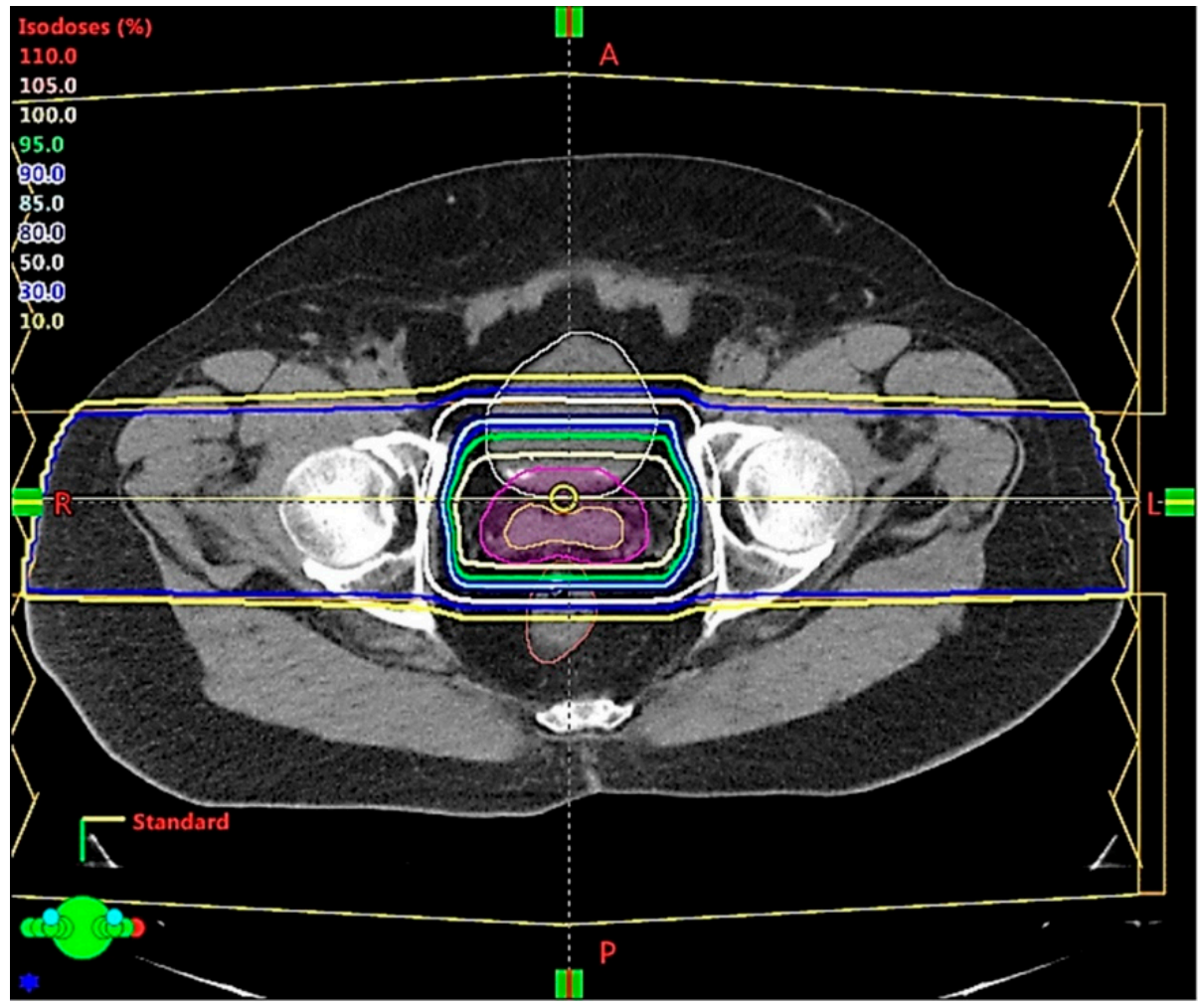

(A)

Figure 2. Cont. 


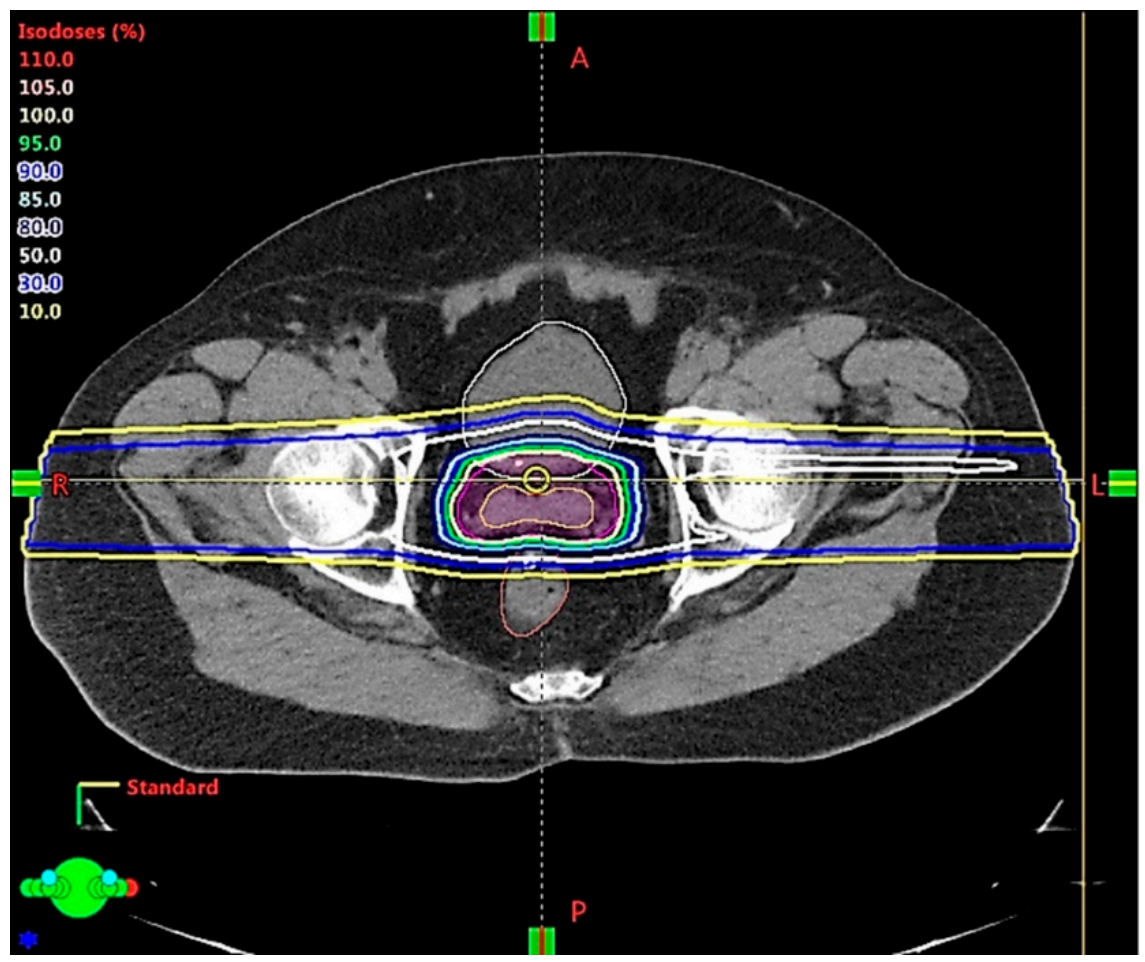

(B)

Figure 2. Isodose distribution comparison of two different proton therapy techniques: conventional passive scattering (A) and modern intensity-modulated proton therapy (IMPT) (B). IMPT shows improved dose conformity near critical organs.

Proton range uncertainty is one factor that can severely compromise dose conformity and affect treatment outcome. For instance, in their study on head and neck treatments, Tattenberg et al. found that a reduction from the currently adopted range uncertainty of approximately $4 \%$ to a potentially achievable level of $1 \%$ could reduce the probability of brainstem necrosis by up to $1.3 \%$ in the nominal scenario, and by up to $2.9 \%$ in the worst-case scenario [58].

Proton range uncertainties are mainly caused by uncertainties arising from: (1) errors introduced when deriving the mass density or SPR for PT dose calculation in treatment planning; and (2) patient positioning errors introduced during treatment setup. We have performed simulated studies on the dosimetric effects of different robust optimization scenarios of range and setup uncertainties in IMPT prostate plans. The results from nominal plans are presented in Table 1, and clearly demonstrate a dependence of critical normal organ dose on setup uncertainties. There is a minor dosimetric effect for range uncertainty because of the bilateral delivered beam in prostate treatment. The non-target tissue was defined as body tissue that excludes the clinical target volume (CTV) and limits the region between $1 \mathrm{~cm}$ superior and inferior from the CTV. Such uncertainties should be minimized before the dosimetric benefits of PT can be realized as clinical benefits in prostate treatment. 
Table 1. Comparative effects of simulated robust optimization uncertainties in proton beam range and setup on dosimetry in a prostate intensity-modulated proton therapy (IMPT) planning system.

\begin{tabular}{|c|c|c|c|c|c|c|c|c|c|}
\hline \multicolumn{10}{|c|}{ Clinical Scenarios } \\
\hline Range uncertainty & & & & & $3.0 \%$ & $2.5 \%$ & $2.0 \%$ & $1.5 \%$ & $1.0 \%$ \\
\hline Setup error & $5 \mathrm{~mm}$ & $3 \mathrm{~mm}$ & $2 \mathrm{~mm}$ & $1 \mathrm{~mm}$ & & & $1 \mathrm{~mm}$ & & \\
\hline CTV, $\mathrm{V}_{78 \mathrm{~Gy}}$ & $99.9 \%$ & $99.6 \%$ & $99.1 \%$ & $98.4 \%$ & $98.8 \%$ & $98.5 \%$ & $98.8 \%$ & $99.3 \%$ & $99.6 \%$ \\
\hline Rectum, $\mathrm{V}_{70 \mathrm{~Gy}}$ & $30.8 \%$ & $25.9 \%$ & $24.5 \%$ & $20.1 \%$ & $19.7 \%$ & $20.1 \%$ & $18.2 \%$ & $19.5 \%$ & $19.5 \%$ \\
\hline Bladder, $V_{70 G y}$ & $35.2 \%$ & $30.6 \%$ & $29.1 \%$ & $25.3 \%$ & $24.7 \%$ & $24.7 \%$ & $24.5 \%$ & $23.6 \%$ & $23.5 \%$ \\
\hline Rectum, $\mathrm{D}_{\text {mean }}(\mathrm{Gy})$ & 37.1 & 33.3 & 32.4 & 28.8 & 28.5 & 28.9 & 27.1 & 28.4 & 28.5 \\
\hline Bladder, $\mathrm{D}_{\text {mean }}(\mathrm{Gy})$ & 40.4 & 37.0 & 36.1 & 32.8 & 32.3 & 32.5 & 32.2 & 31.8 & 31.7 \\
\hline Non-target tissue, $\mathrm{D}_{\text {mean }}(\mathrm{Gy})$ & 14.6 & 13.6 & 13.3 & 12.3 & 12.1 & 12.1 & 11.7 & 11.8 & 11.7 \\
\hline
\end{tabular}

Non-target tissue describes body tissue that excludes the clinical target volume (CTV) and limits the region between $1 \mathrm{~cm}$ superior and inferior from the CTV.

In traditional PT of prostate cancer, large margins are used to account for the two major sources of uncertainties mentioned above. Such planning strategies may compromise the dose conformity of the treatment, thereby affecting the clinical outcome. These uncertainties can now be minimized using new technologies and innovative techniques in the PT workflow, as discussed below.

1. The large uncertainties in CT HU values, and CT conversion to mass density or SPR $[45,50]$, can now be overcome by modern $\mathrm{CT}$, which can acquire mass density maps or SPR directly [59] from CT image reconstruction data. Mass density and SPR are less sensitive to patient scan conditions than HU [60], and thus have less uncertainty. With this approach, the range uncertainty could be decreased from $3.5 \%$ to $2-2.5 \%$. There is also an increasing interest in dual energy CT (DECT) as an alternative imaging modality for PT treatment planning because of its ability to discriminate between changes in patient density and chemical composition [61]. SPR calculation accuracy was found to be superior, on average, for DECT relative to single energy CT (SECT). Maximum errors of $12.8 \%$ and $2.2 \%$ were found in SPR data derived from SECT imaging and DECT imaging, respectively [61]. Quantitatively, the maximum dose calculation error in the SECT plan was $7.8 \%$, compared to a value of $1.4 \%$ in the DECT plan [62]. Additionally, a novel spectral CT imaging technique based on a dual-layer detector-based approach has been used to demonstrate improvement in SPR prediction for particle therapy treatment planning, and would minimize the beam range uncertainty, allowing for the use of reduced safety margins in patient plans [63].

2. Because of the inferior soft tissue contrast, orthogonal X-ray imaging systems rely on bony structures for verification of treatment position during patient setup. This type of setup technique can result in large positioning errors due to daily movement of the target and organs at risk (OARs) relative to the bony structures in the former technique. With fiducial markers implanted inside the prostate, many studies concluded that image registration by fiducial markers would reduce matching error. However, some patients may not accept marker implantation. Migration of markers with time may introduce registration errors. Such problems can now be minimized using on-board cone beam CT (CBCT). The better image quality of CBCT can provide 3D images and more information on the anatomic relationships between organs $[64,65]$, which can be used to improve the accuracy of patient setup. Besides patient positioning, CBCT images can also provide information about inter-fractional changes in patient anatomy. In a recent study, an image-based correction method to generate pseudoCT images from CBCT images was investigated for possible application in proton dose calculations [66] in adaptive PT. MRI, which has the ability to offer fast real- 
time imaging with high soft tissue contrast in the absence of ionizing radiation exposure [67], is being investigated for use in patient setup in RT. Our study using an external MRI setup room [68] and studies by others [69] indicated that patient positioning accuracy on the order of $1 \mathrm{~mm}$ is feasible, and is a significant reduction from that of conventional setup systems.

Improving the levels of accuracy in determining the penetration ranges of proton beams and positioning patients for treatment can facilitate better organ sparing, as illustrated in Table 1. Reduction in PT range and patient positioning uncertainties can also help improve dose conformity in PT treatment, leading to better protection of normal tissues and reduced toxicity, and facilitating the possibility of dose escalation to improve local control. The concept of in-room or integrated MRI-guided PT, although still investigational, is gaining momentum [70-72]. Integrated PT with MR gantry systems have created many engineering problems that must be overcome. Deflection of complex charge particles observed in magnetic fields changed the direction vectors, depending on the energy and heterogeneity. Optimized IMPT plans should account for the scanning beam in the complex fringe field. Compared with integrated MRI-guided PT, there is less uncertainty in a PT system combined with in-room MRI equipment. With in-room or on-line MRI-guided patient positioning, as illustrated in Figure 3 (upper panel), further improvements in accuracy and dose conformity in PT treatment are possible, and we should remember that MRI delivers superior soft-tissue contrast compared with CT (lower panel). Development of such a treatment modality will be technologically and economically challenging, and is unlikely to be accomplished in the near future.

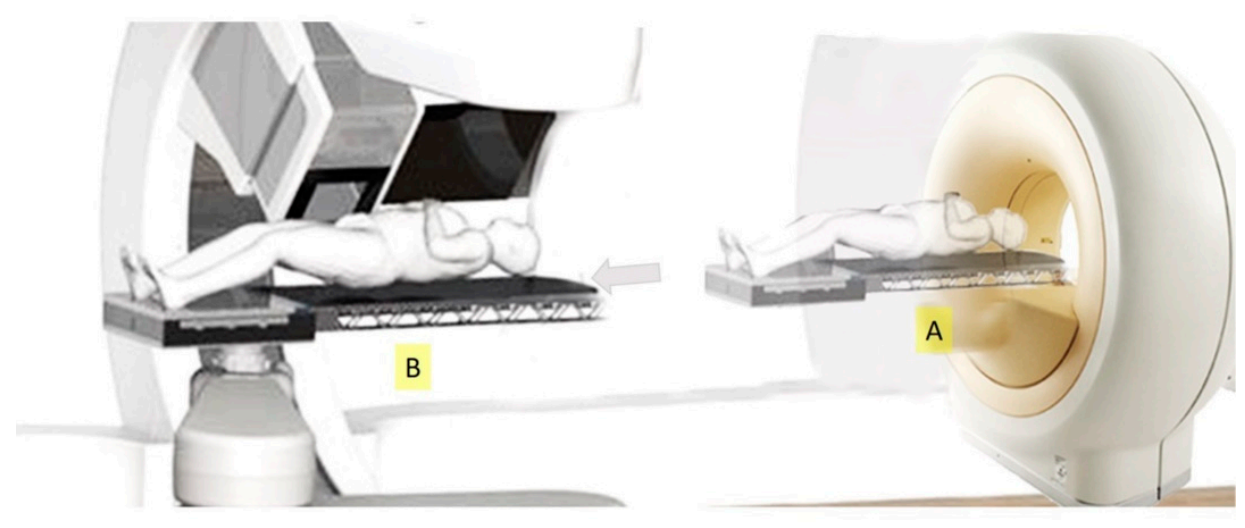

(A)
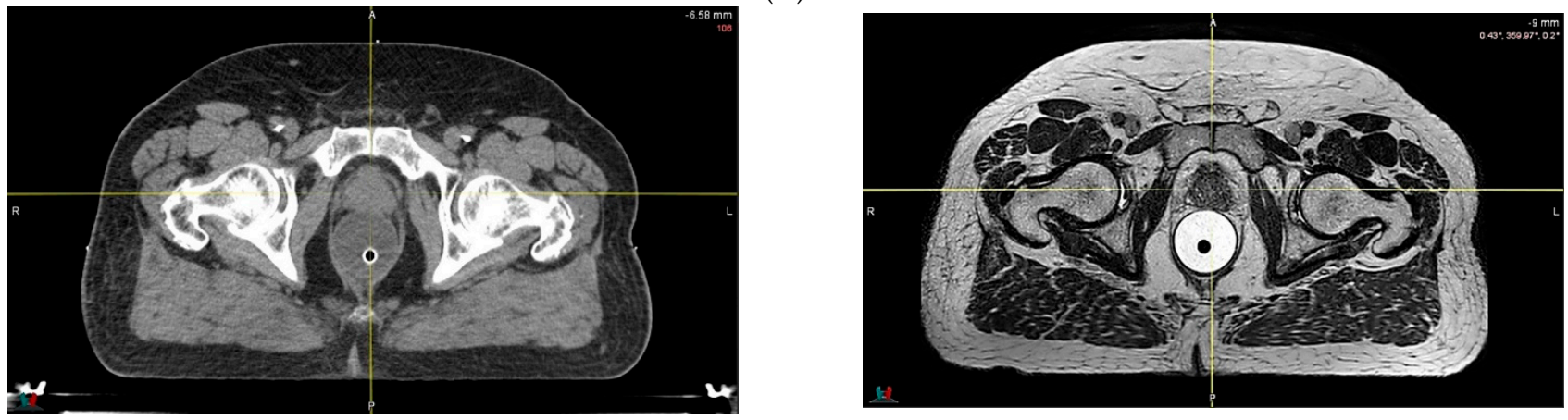

(B)

Figure 3. (A) Diagram of a proton therapy system with in-room magnetic resonance (MR). MR images are acquired first, with the patient lying on a robotic couch in position A, followed by relocation to position B for proton delivery, directly after image registration. (B) Comparison of computed tomography and MR images of prostate cancer. 
Significant advancements in treatment planning system (TPS) technology have also been made in recent years. The MC-based TPS dose calculation algorithm is considered to be the most accurate method, and it has been demonstrated that it could lead to a significant reduction in treatment planning margins $[50,73]$. However, the lengthy time required for MC-based dose calculations in the past was impractical for routine clinical treatment planning. In recent years, computer graphic processing units (GPUs) have drawn great attention due to their tremendous ability to accelerate a variety of computationally intensive tasks. A TPS running on a GPU computer makes the MC-based dose calculation algorithm in RT treatment planning feasible. TPS options based on simplified MC algorithms and GPU computers are now commercially available for routine clinical use. Because of these efforts, the calculation time of MC-based proton dose calculation has been significantly shortened. MC-based dose planning and calculation in PT is now becoming routine, helping to reduce treatment uncertainties. Additionally, the resolution of dose grid and MC simulation uncertainties are improved with a GPU-based TPS, further improving the dosimetric accuracy of the treatment plans.

As mentioned earlier, PT is very sensitive to changes in the position and shape of the target and OARs in patients, both between treatment fractions and within a fraction. With reduction in treatment uncertainties and higher dose conformity, accurate quality assurance $(\mathrm{QA})$ verification of the treatment plan, especially treatment geometry at every treatment fraction, is essential. Several efforts [74] are ongoing to develop new QA tools and techniques that can be used to ensure geometric and dosimetric accuracies of PT treatments. QA tools and techniques based on proton radiography and tomography, positron emission tomography, and prompt gamma imaging are under investigation. Currently, verification of proton range in vivo is mostly based on detection of secondary radiation, such as prompt gamma rays [75]. Various approaches to on-line monitoring of PT have been reported, and some have already been successfully tested clinically with patients [76]. A recent European Society for Radiotherapy and Oncology conference (ESTRO 2020) revealed a new study of on-line MRI that verified the proton beam range of PT [77]. PT range verification using positron emission tomography has been investigated at several institutions [78].

TPS with robust planning optimization that accounts for uncertainties that cannot be corrected (e.g., movement of the target and critical OARs during treatment) are in routine clinical application. This technique helps to predict and illustrate the actual dose to be delivered to the patient, which in turn can further improve dose optimization and clinical decision making. The uncertainty in RBE is a dosimetric issue under active investigation, with the aim to improve the accuracy of patient dose. TPS dosimetry algorithms are available that test the dependency of RBE on the LET of protons. It is well-known that the current adopted average RBE value of 1.1 assumes that proton doses are about $10 \%$ more biologically damaging than MV X-ray RT. However, experimental data indicate that RBE depends on dose, LET and $\alpha / \beta$ ratio [79-83], as protons traversing a patient change energy as they travel. They have higher LET at the distal end of an SOBP, and such variations, if not taken into account in dose calculation, can theoretically have an impact on patient dosimetry. Clinical evidence on the effect of RBE variations on treatment outcome has yet to be reported. By contrast, biological treatment planning and LET-guided dose optimization have been developed and commercially available for testing and clinic planning studies. They are mainly used in generating reference plans with LET-based dose optimization for guiding the planning of complex treatment involving critical normal tissue structures [84-86]. Subject to satisfactory demonstration of clinical evidence, LET-based dose optimization may potentially improve the quality of PT treatment plans.

MC-based algorithms calculate the variable RBE from the LET of the proton interactions at different locations in the patient, and incorporate the variable RBE data into patient dose calculation and optimization. As a result, a theoretically more accurate dose map of the target and OARs of the treatment can be constructed. This information can serve as a valuable reference for protecting OARs from excessive dose $[87,88]$. In the case of prostate 
treatment, if variance of RBE is incorporated into robust optimization, biological dose for critical organs such as the rectum and bladder could be minimized to protect these organs.

Additionally, LET-based dose optimization will be applied to the treatment plan, which provides a useful reference map for plan assessment. All of the new technologies mentioned above provide us with the appropriate tools to go a step further with treatment of the prostate using PT. DECT and spectral CT reduce conventional CT uncertainty and handle well-defined shrunken tumor margins. By applying the use of implanted fiducial markers, CBCT or in-room MR imaging guided system, setup errors could be controlled to within a relatively small amount. Furthermore, the new technological developments described above will better protect critical organs from unnecessary radiation dose.

\section{Potential Clinical Benefits and Cost Effectiveness of PT in Treatment of Prostate Cancer}

The overall survival of localized prostate cancer patients treated with PT, photon-based EBRT, and brachytherapy in the US between 2004 and 2015 were analyzed and compared by Liu et al. [89]. They concluded that PT was associated with a significant overall survival benefit compared to EBRT, and delivered outcomes were similar to brachytherapy. PARTIQoL, an ongoing phase III randomized trial [NCT01617161], will determine whether IMRT or PT best minimizes the side effects of treatment for low- or intermediate-risk prostate cancer. Another ongoing study, COMPARE [NCT03561220], will compare the patient-centric outcomes (quality of life, toxicity, and disease control) between parallel cohorts of men with prostate cancer treated simultaneously at PT facilities and at geographically similar conventional IMRT facilities. With the latest generation of PT technologies and high-precision innovative treatment and pre-treatment techniques that have been developed to improve the accuracy and quality of PT treatment, we can soon expect to see clinical data with more favorable outcomes in prostate treatment using PT. Dose escalation is one treatment strategy that may now be safely implemented to improve local control, and yet an important question remains: is dose escalation with PT superior to photon-based treatment? Based on the fundamental principles of dose-response characteristics in RT, it is likely that the dosimetric advantages of PT, particularly regarding dose escalation, will translate into clinical benefits and outperform conventional EBRT. With better dose conformity, more appropriately escalated dose prescriptions to the target, together with clinically acceptable OAR dose constraints, can be used in PT treatments. Additionally, the dosimetric advantages of PT in prostate treatment can be enhanced further by the use of rectal spacers [90,91], particularly when IMPT is used [92,93]. Apart from toxicity, studies comparing IMRT versus 3D-conformal RT [94] and IMRT versus PT [95] suggest that conformity of the treatment is associated with the risk of radiation-induced second malignancies. Based on organ equivalent dose calculations, the risk of secondary malignancies in out-of-field organs, including the stomach, lungs and thyroid, was at least 5 times higher for IMRT than for PT in prostate treatment. In the prostate, smaller irradiated volume to normal tissue and lower integral non-target dose in PT may reduce the risk of secondary malignancies. Furthermore, a lower OAR dose from previous delivery also favors re-treatment upon recurrence and successive treatment [96].

The cost-effectiveness of PT has been questionable, mainly due to the high infrastructure and machinery costs [97]. In a systematic review that analyzed the costs and cost-effectiveness of PT for different disease types [98], Verma et al. indicated that the costeffectiveness of PT is generally lower for low-risk prostate cancer. While patient selection plays a crucial role in such analyses, with considerations of treatment efficacy and costs associated with acute/late toxicities, we note that the cost of PT is coming down as the technology advances. The weight and size of accelerators and gantries have been decreased by half since the 1990s [99], and novel designs with superconducting magnets have been proposed that would significantly scale down their sizes even further [100]. The upfront costs for infrastructure and machine units are on a downward trend. Regarding operational costs, IMPT is theoretically cost saving compared with passive scattering PT, which involves the use of a patient-specific brass aperture and compensator; however, few studies have 
discussed this cost implication [9]. Moreover, a number of clinical trials have suggested a higher therapeutic ratio for hypo-fractionation in low $\alpha / \beta$ prostate cancer [101-103]. Improvement in dose conformity in PT treatment may allow hypo-fractionation treatment schemes to be implemented as the standard of care, which can effectively increase patient throughput [104]. The concept of remote patient positioning in the patient setup room may also increase patient throughput $[105,106]$. Collectively, these efforts at making PT more accurate and efficient will surely improve the efficacy and cost effectiveness of PT in the treatment of prostate cancer.

\section{Conclusions}

Despite its dosimetric advantage, the use of PT for the treatment of prostate cancer has been limited, mainly by inadequate dose prescription and improper dose delivery. Advanced high-precision PT technologies, dose planning and beam delivery techniques have been developed and commercially available for implementation and are expected to optimize the dose conformity of PT in prostate treatment. Improvement in dose conformity can enhance local disease control, patient throughput and cost-effectiveness by allowing for implementation of dose escalation and hypofractionation treatment schemes.

Author Contributions: Conceptualization, visualization and validation: D.M.C.P.; methodology and original draft preparation: K.Y.C.; writing-review and editing: S.W. and L.H.; project administration, B.Y. All authors have read and agreed to the published version of the manuscript.

Funding: This research received no external funding.

Acknowledgments: The authors would like to acknowledge the full support given by the Medical Physics Department of Hong Kong Sanatorium \& Hospital.

Conflicts of Interest: The authors declare no conflict of interest.

\section{References}

1. Endo, M.; Robert, R.W. (1914-2000): The first scientist to propose particle therapy-Use of particle beam for cancer treatment. Radiol. Phys. Technol. 2018, 11, 1-6. [CrossRef]

2. Chera, B.S.; Vargas, C.; Morris, C.G.; Louis, D.; Flampouri, S.; Yeung, D.; Duvvuri, S.; Li, Z.; Mendenhall, N.P. Dosimetric study of pelvic proton radiotherapy for high-risk prostate cancer. Int. J. Radiat. Oncol. 2009, 75, 994-1002. [CrossRef] [PubMed]

3. Rana, S.; Rogers, K.; Lee, T.; Reed, D.; Biggs, C. Dosimetric impact of Acuros XB dose calculation algorithm in prostate cancer treatment using RapidArc. J. Cancer Res. Ther. 2013, 9, 430. [CrossRef]

4. Lawrence, J.H. Proton irradiation of the pituitary. Cancer 1957, 10, 795-798. [CrossRef]

5. Smith, A.R. Proton therapy. Phys. Med. Biol. 2006, 51, R491-R504. [CrossRef]

6. The National Association for Proton Therapy. Proton Therapy Fact Sheet. Available online: https://www.proton-therapy.org/ patient-resources / fact-sheet/ (accessed on 24 November 2021).

7. Particle Therapy Co-Operative Group. Available online: https://www.ptcog.ch/ (accessed on 31 December 2020).

8. Pan, H.Y.; Jiang, J.; Hoffman, K.E.; Tang, C.; Choi, S.L.; Nguyen, Q.-N.; Frank, S.J.; Anscher, M.S.; Shih, Y.-C.T.; Smith, B.D. Comparative toxicities and cost of intensity-modulated radiotherapy, proton radiation, and stereotactic body radiotherapy among younger men with prostate cancer. J. Clin. Oncol. 2018, 36, 1823-1830. [CrossRef] [PubMed]

9. Mohan, R.; Grosshans, D. Proton therapy-Present and future. Adv. Drug Deliv. Rev. 2017, 109, 26-44. [CrossRef] [PubMed]

10. Schulz-Ertner, D.; Tsujii, H. Particle radiation therapy using proton and heavier ion beams. J. Clin. Oncol. 2007, 25, 953-964. [CrossRef] [PubMed]

11. Morris, W.J.; Tyldesley, S.; Rodda, S.; Halperin, R.; Pai, H.; McKenzie, M.; Duncan, G.; Morton, G.; Hamm, J.; Murray, N. Androgen suppression combined with elective nodal and dose escalated radiation therapy (the ASCENDE-RT Trial): An analysis of survival endpoints for a randomized trial comparing a low-dose-rate brachytherapy boost to a dose escalated external beam boost for high- and intermediate-risk prostate cancer. Int. J. Radiat. Oncol. Biol. Phys. 2017, 98, 275-285. [CrossRef] [PubMed]

12. Liu, W.; Mohan, R.; Park, P.; Liu, Z.; Li, H.; Li, X.; Li, Y.; Wu, R.; Sahoo, N.; Dong, L.; et al. Dosimetric benefits of robust treatment planning for intensity modulated proton therapy for base-of-skull cancers. Pract. Radiat. Oncol. 2014, 4, 384-391. [CrossRef]

13. Vargas, C.; Fryer, A.; Mahajan, C.; Indelicato, D.; Horne, D.; Chellini, A.; McKenzie, C.; Lawlor, P.; Henderson, R.; Li, Z.; et al. Dose-volume comparison of proton therapy and intensity-modulated radiotherapy for prostate cancer. Int. J. Radiat. Oncol. 2008, 70, 744-751. [CrossRef]

14. Mock, D.D.U.; Bogner, J.; Georg, D.; Auberger, T.; Pötter, R. Comparative treatment planning on localized prostate carcinoma. Strahlenther. Onkol. 2005, 181, 448-455. [CrossRef] [PubMed] 
15. Cella, L.; Lomax, A.; Miralbell, R. Potential role of intensity modulated proton beams in prostate cancer radiotherapy. Int. J. Radiat. Oncol. 2001, 49, 217-223. [CrossRef]

16. Moteabbed, M.; Trofimov, A.; Sharp, G.C.; Wang, Y.; Zietman, A.L.; Efstathiou, J.A.; Lu, H.-M. Proton therapy of prostate cancer by anterior-oblique beams: Implications of setup and anatomy variations. Phys. Med. Biol. 2017, 62, 1644-1660. [CrossRef] [PubMed]

17. Cuaron, J.J.; Harris, A.A.; Chon, B.; Tsai, H.; Larson, G.; Hartsell, W.F.; Hug, E.; Cahlon, O. Anterior-oriented proton beams for prostate cancer: A multi-institutional experience. Acta Oncol. 2015, 54, 868-874. [CrossRef]

18. Polf, J.C.; Chuong, M.; Zhang, B.; Mehta, M. Anteriorly oriented beam arrangements with daily in vivo range verification for proton therapy of prostate cancer: Rectal toxicity rates. Int. J. Part. Ther. 2016, 2, 509-517. [CrossRef]

19. Murray, L.; Henry, A.; Hoskin, P.; Siebert, F.-A.; Venselaar, J. Second primary cancers after radiation for prostate cancer: A systematic review of the clinical data and impact of treatment technique. Radiother. Oncol. 2014, 110, 213-228. [CrossRef]

20. Davis, E.J.; Beebe-Dimmer, J.L.; Ms, C.L.Y.; Cooney, K.A. Risk of second primary tumors in men diagnosed with prostate cancer: A population-based cohort study. Cancer 2014, 120, 2735-2741. [CrossRef]

21. Slater, J.D.; Rossi, C.J.; Yonemoto, L.T.; Bush, D.; Jabola, B.; Levy, R.P.; Grove, R.I.; Preston, W.; Slater, J.M. Proton therapy for prostate cancer: The initial Loma Linda University experience. Int. J. Radiat. Oncol. 2004, 59, 348-352. [CrossRef]

22. Vassil, A.D.; Murphy, E.S.; Reddy, C.A.; Angermeier, K.W.; Altman, A.; Chehade, N.; Ulchaker, J.; Klein, E.A.; Ciezki, J.P. Five year biochemical recurrence free survival for intermediate risk prostate cancer after radical prostatectomy, external beam ra-diation therapy or permanent seed implantation. Urology 2010, 76, 1251-1257. [CrossRef]

23. Coen, J.J.; Zietman, A.L.; Rossi, C.J.; Grocela, J.A.; Efstathiou, J.A.; Yan, Y.; Shipley, W.U. Comparison of high-dose proton radiotherapy and brachytherapy in localized prostate cancer: A case-matched analysis. Int. J. Radiat. Oncol. 2012, 82, e25-e31. [CrossRef] [PubMed]

24. Takagi, M.; Demizu, Y.; Fujii, O.; Terashima, K.; Niwa, Y.; Daimon, T.; Tokumaru, S.; Fuwa, N.; Hareyama, M.; Okimoto, T. Proton therapy for localized prostate cancer: Long-term results from a single-center experience. Int. J. Radiat. Oncol. 2020, 109, 964-974. [CrossRef] [PubMed]

25. Gray, P.J.; Bs, J.J.P.; Yeap, B.Y.; Sanda, M.G.; Sandler, H.M.; Michalski, J.M.; Talcott, J.A.; Coen, J.J.; Hamstra, D.A.; Shipley, W.U.; et al. Patient-reported outcomes after 3-dimensional conformal, intensity-modulated, or proton beam radiotherapy for localized prostate cancer. Cancer 2013, 119, 1729-1735. [CrossRef] [PubMed]

26. Hoppe, B.S.; Michalski, J.M.; Mendenhall, N.; Ms, C.G.M.; Henderson, R.; Nichols, R.C.; Mendenhall, W.M.; Williams, C.R.; Regan, M.M.; Ms, J.J.C.; et al. Comparative effectiveness study of patient-reported outcomes after proton therapy or intensity-modulated radiotherapy for prostate cancer. Cancer 2013, 120, 1076-1082. [CrossRef] [PubMed]

27. Fang, P.; Ms, R.M.; Deville, C.; Both, S.; Bekelman, J.E.; Christodouleas, J.P.; Guzzo, T.J.; Tochner, Z.; Hahn, S.M.; Vapiwala, N. A case-matched study of toxicity outcomes after proton therapy and intensity-modulated radiation therapy for prostate cancer. Cancer 2014, 121, 1118-1127. [CrossRef]

28. Kim, S.; Shen, S.; Moore, D.F.; Shih, W.; Lin, Y.; Li, H.; Dolan, M.; Shao, Y.-H.; Lu-Yao, G.L. Late gastrointestinal toxicities following radiation therapy for prostate cancer. Eur. Urol. 2011, 60, 908-916. [CrossRef] [PubMed]

29. Yu, J.B.; Soulos, P.R.; Herrin, J.; Cramer, L.D.; Potosky, A.L.; Roberts, K.B.; Gross, C.P. Proton versus intensity-modulated radiotherapy for prostate cancer: Patterns of care and early toxicity. JNCI J. Natl. Cancer Inst. 2013, 105, 25-32. [CrossRef]

30. Royce, T.J.; Lee, D.H.; Keum, N.; Permpalung, N.; Chiew, C.J.; Epstein, S.; Pluchino, K.M.; D'Amico, A.V. Conventional versus hypofractionated radiation therapy for localized prostate cancer: A meta-analysis of randomized noninferiority trials. Eur. Urol. Focus 2017, 5, 577-584. [CrossRef]

31. Al-Mamgani, A.; van Putten, W.L.; Heemsbergen, W.D.; van Leenders, G.J.; Slot, A.; Dielwart, M.F.; Incrocci, L.; Lebesque, J.V. Update of Dutch multicenter dose-escalation trial of radiotherapy for localized prostate cancer. Int. J. Radiat. Oncol. 2008, 72 , 980-988. [CrossRef]

32. Dearnaley, D.P.; Jovic, G.; Syndikus, I.; Khoo, V.; Cowan, R.; Graham, J.; Aird, E.G.; Bottomley, D.; Huddart, R.A.; Jose, C.C.; et al. Escalated-dose versus control-dose conformal radiotherapy for prostate cancer: Long-term results from the MRC RT01 randomised controlled trial. Lancet Oncol. 2014, 15, 464-473. [CrossRef]

33. Kuban, D.A.; Tucker, S.L.; Dong, L.; Starkschall, G.; Huang, E.H.; Cheung, M.R.; Lee, A.K.; Pollack, A. Long-term results of the M. D. Anderson randomized dose-escalation trial for prostate cancer. Int. J. Radiat. Oncol. Biol. Phys. 2008, 70, 67-74. [CrossRef] [PubMed]

34. Beckendorf, V.; Guerif, S.; Le Prisé, E.; Cosset, J.-M.; Bougnoux, A.; Chauvet, B.; Salem, N.; Chapet, O.; Bourdain, S.; Bachaud, J.-M.; et al. 70 Gy versus 80 Gy in localized prostate cancer: 5-year results of GETUG 06 randomized trial. Int. J. Radiat. Oncol. Biol. Physics. 2011, 80, 1056-1063. [CrossRef]

35. Zietman, A.L.; Bae, K.; Slater, J.D.; Shipley, W.U.; Efstathiou, J.A.; Coen, J.J.; Bush, D.A.; Lunt, M.; Spiegel, D.Y.; Skowronski, R.; et al. Randomized trial comparing conventional-dose with high-dose conformal radiation therapy in early-stage adenocarcinoma of the prostate: Long-term results from Proton Radiation Oncology Group/American College of Radiology 95-09. J. Clin. Oncol. 2010, 28, 1106-1111. [CrossRef]

36. Sheets, N.C.; Goldin, G.H.; Meyer, A.-M.; Wu, Y.; Chang, Y.; Stürmer, T.; Holmes, J.A.; Reeve, B.B.; Godley, P.A.; Carpenter, W.R.; et al. Intensity-modulated radiation therapy, proton therapy, or conformal radiation therapy and morbidity and disease control in localized prostate cancer. JAMA 2012, 307, 1611-1620. [PubMed] 
37. Rodda, S.; Tyldesley, S.; Morris, W.J.; Keyes, M.; Halperin, R.; Pai, H.; McKenzie, M.; Duncan, G.; Morton, G.; Hamm, J.; et al. ASCENDE-RT: An analysis of treatment-related morbidity for a randomized trial comparing a low-dose-rate brachytherapy boost with a dose-escalated external beam boost for high- and intermediate-risk prostate cancer. Int. J. Radiat. Oncol. 2017, 98, 286-295. [CrossRef]

38. Paganetti, H. Relative biological effectiveness (RBE) values for proton beam therapy. Variations as a function of biological endpoint, dose, and linear energy transfer. Phys. Med. Biol. 2014, 59, R419-R472. [CrossRef] [PubMed]

39. Soukup, M.; Alber, M. Influence of dose engine accuracy on the optimum dose distribution in intensity-modulated proton therapy treatment plans. Phys. Med. Biol. 2007, 52, 725-740. [CrossRef]

40. Szymanowski, H.; Oelfke, U. Two-dimensional pencil beam scaling: An improved proton dose algorithm for heterogeneous media. Phys. Med. Biol. 2002, 47, 3313-3330. [CrossRef] [PubMed]

41. Titt, U.; Sahoo, N.; Ding, X.; Zheng, Y.; Newhauser, W.D.; Zhu, X.R.; Polf, J.C.; Gillin, M.T.; Mohan, R. Assessment of the accuracy of an MCNPX-based Monte Carlo simulation model for predicting three-dimensional absorbed dose distributions. Phys. Med. Biol. 2008, 53, 4455-4470. [CrossRef]

42. Petti, P.L. Evaluation of a pencil-beam dose calculation technique for charged particle radiotherapy. Int. J. Radiat. Oncol. 1996, 35, 1049-1057. [CrossRef]

43. Schaffner, B.; Pedroni, E.; Lomax, A. Dose calculation models for proton treatment planning using a dynamic beam delivery system: An attempt to include density heterogeneity effects in the analytical dose calculation. Phys. Med. Biol. 1999, 44, 27-41. [CrossRef] [PubMed]

44. Holloway, S.M.; Holloway, M.D.; Thomas, S. A method for acquiring random range uncertainty probability distributions in proton therapy. Phys. Med. Biol. 2017, 63, 01NT02. [CrossRef] [PubMed]

45. Chvetsov, A.V.; Paige, S.L. The influence of CT image noise on proton range calculation in radiotherapy planning. Phys. Med. Biol. 2010, 55, N141-N149. [CrossRef] [PubMed]

46. Newhauser, W.D.; Giebeler, A.; Langen, K.M.; Mirkovic, D.; Mohan, R. Can megavoltage computed tomography reduce proton range uncertainties in treatment plans for patients with large metal implants? Phys. Med. Biol. 2008, 53, 2327-2344. [CrossRef] [PubMed]

47. Jäkel, O.; Reiss, P. The influence of metal artefacts on the range of ion beams. Phys. Med. Biol. 2007, 52, 635-644. [CrossRef]

48. Yang, M.; Zhu, X.R.; Park, P.C.; Titt, U.; Mohan, R.; Virshup, G.; Clayton, J.E.; Dong, L. Comprehensive analysis of proton range uncertainties related to patient stopping-power-ratio estimation using the stoichiometric calibration. Phys. Med. Biol. 2012, 57, 4095-4115. [CrossRef]

49. Wohlfahrt, P.; Richter, C. Status and innovations in pre-treatment CT imaging for proton therapy. Br. J. Radiol. 2020, 93. [CrossRef]

50. Paganetti, H. Range uncertainties in proton therapy and the role of Monte Carlo simulations. Phys. Med. Biol. 2012, 57, R99-R117. [CrossRef]

51. Moyers, M.F. Comparison of $\mathrm{x}$ ray computed tomography number to proton relative linear stopping power conversion functions using a standard phantom. Med. Phys. 2014, 41, 061705. [CrossRef]

52. Park, P.C.; Cheung, J.P.; Zhu, X.R.; Lee, A.K.; Sahoo, N.; Tucker, S.L.; Liu, W.; Li, H.; Mohan, R.; Court, L.; et al. Statistical assessment of proton treatment plans under setup and range uncertainties. Int. J. Radiat. Oncol. Biol. Phys. 2013, 86, 1007-1013. [CrossRef]

53. Wouters, B.G.; Skarsgard, L.D.; Gerweck, L.E.; Cárabe-Fernández, A.; Wong, M.; Durand, R.E.; Nielson, D.; Bussière, M.R.; Wagner, M.; Biggs, P.; et al. Radiobiological intercomparison of the $160 \mathrm{MeV}$ and $230 \mathrm{MeV}$ proton therapy beams at the Harvard Cyclotron Laboratory and at Massachusetts General Hospital. Radiat. Res. 2015, 183, 174-187. [CrossRef] [PubMed]

54. Maeda, K.; Yasui, H.; Matsuura, T.; Yamamori, T.; Suzuki, M.; Nagane, M.; Nam, J.-M.; Inanami, O.; Shirato, H. Evaluation of the relative biological effectiveness of spot-scanning proton irradiation in vitro. J. Radiat. Res. 2016, 57, 307-311. [CrossRef] [PubMed]

55. Mairani, A.; Dokic, I.; Magro, G.; Tessonnier, T.; Bauer, J.; Böhlen, T.T.; Ciocca, M.; Ferrari, A.; Sala, P.; Jäkel, O.; et al. A phenomenological relative biological effectiveness approach for proton therapy based on an improved description of the mixed radiation field. Phys. Med. Biol. 2017, 62, 1378-1395. [CrossRef] [PubMed]

56. Thomas, S.J. Margins for treatment planning of proton therapy. Phys. Med. Biol. 2006, 51, 1491-1501. [CrossRef] [PubMed]

57. Royce, T.J.; Efstathiou, J.A. Proton therapy for prostate cancer: A review of the rationale, evidence, and current state. Urol. Oncol. Semin. Orig. Investig. 2019, 37, 628-636. [CrossRef] [PubMed]

58. Tattenberg, S.; Madden, T.M.; Gorissen, B.L.; Bortfeld, T.; Parodi, K.; Verburg, J. Proton range uncertainty reduction benefits for skull base tumors in terms of normal tissue complication probability (NTCP) and healthy tissue doses. Med. Phys. 2021, 48, 5356-5366. [CrossRef] [PubMed]

59. van der Heyden, B.; Öllers, M.; Ritter, A.; Verhaegen, F.; van Elmpt, W. Clinical evaluation of a novel CT image reconstruction algorithm for direct dose calculations. Phys. Imaging Radiat. Oncol. 2017, 2, 11-16. [CrossRef]

60. Zhao, T.; Mistry, N.; Ritter, A.; Sun, B.; Li, H.; Mutic, S. Dosimetric evaluation of direct electron density computed tomography images for simplification of treatment planning workflow. Int. J. Radiat. Oncol. 2016, 96, E674-E675. [CrossRef]

61. Bär, E.; Lalonde, A.; Royle, G.; Lu, H.-M.; Bouchard, H. The potential of dual-energy CT to reduce proton beam range uncertainties. Med. Phys. 2017, 44, 2332-2344. [CrossRef]

62. Zhu, J.; Penfold, S.N. Dosimetric comparison of stopping power calibration with dual-energy CT and single-energy CT in proton therapy treatment planning. Med. Phys. 2016, 43, 2845-2854. [CrossRef] 
63. Faller, F.K.; Mein, S.; Ackermann, B.; Debus, J.; Stiller, W.; Mairani, A. Pre-clinical evaluation of dual-layer spectral computed tomography-based stopping power prediction for particle therapy planning at the Heidelberg Ion Beam Therapy Center. Phys. Med. Biol. 2020, 65, 095007. [CrossRef] [PubMed]

64. Landry, G.; Hua, C. Current state and future applications of radiological image guidance for particle therapy. Med. Phys. 2018, 45, e1086-e1095. [CrossRef] [PubMed]

65. Posiewnik, M.; Piotrowski, T. A review of cone-beam CT applications for adaptive radiotherapy of prostate cancer. Phys. Med. 2019, 59, 13-21. [CrossRef] [PubMed]

66. Thummerer, A.; Zaffino, P.; Meijers, A.; Marmitt, G.G.; Seco, J.; Steenbakkers, R.J.H.M.; Langendijk, J.A.; Both, S.; Spadea, M.F.; Knopf, A.-C. Comparison of CBCT based synthetic CT methods suitable for proton dose calculations in adaptive proton therapy. Phys. Med. Biol. 2020, 65, 095002. [CrossRef]

67. Wyatt, J.J.; Brooks, R.L.; Ainslie, D.; Wilkins, E.; Raven, E.; Pilling, K.; Pearson, R.A.; McCallum, H.M. The accuracy of Magnetic Resonance-Cone Beam Computed Tomography soft-tissue matching for prostate radiotherapy. Phys. Imaging Radiat. Oncol. 2019, 12, 49-55. [CrossRef] [PubMed]

68. Businesswire. Hong Kong Sanatorium Radiotherapy Department and MedLever to Streamline Patient Setup \& Imaging Process. Available online: https://www.businesswire.com/news/home/20170913005133/en/Hong-Kong-Sanatorium-RadiotherapyDepartment-and-MedLever-To-Streamline-Patient-Setup-Imaging-Process (accessed on 24 November 2021).

69. Nyholm, T.; Nyberg, M.; Karlsson, M.G.; Karlsson, M. Systematisation of spatial uncertainties for comparison between a MR and a CT-based radiotherapy workflow for prostate treatments. Radiat. Oncol. 2009, 4, 54. [CrossRef] [PubMed]

70. Hoffmann, A.; Oborn, B.; Moteabbed, M.; Yan, S.; Bortfeld, T.; Knopf, A.; Fuchs, H.; Georg, D.; Seco, J.; Spadea, M.F.; et al MR-guided proton therapy: A review and a preview. Radiat. Oncol. 2020, 15, 129. [CrossRef] [PubMed]

71. Oborn, B.; Dowdell, S.; Metcalfe, P.; Crozier, S.; Mohan, R.; Keall, P. Future of medical physics: Real-time MRI guided proton therapy. Med. Phys. 2017, 44, e77-e90. [CrossRef]

72. Depauw, N.; Keyriläinen, J.; Suilamo, S.; Warner, L.; Bzdusek, K.; Olsen, C.; Kooy, H. MRI-based IMPT planning for prostate cancer. Radiother. Oncol. 2020, 144, 79-85. [CrossRef]

73. Pepin, M.; Tryggestad, E.; Tseung, H.; Johnson, J.; Herman, M.; Beltran, C. A Monte-Carlo-based and GPU-accelerated 4D-dose calculator for a pencil-beam scanning proton therapy system. Med. Phys. 2018, 45, 5293-5304. [CrossRef]

74. Parodi, K.; Polf, J.C. In vivo range verification in particle therapy. Med. Phys. 2018, 45, e1036-e1050. [CrossRef]

75. Wrońska, A. Prompt gamma imaging in proton therapy-Status, challenges and developments. J. Phys. Conf. Ser. 2020, 1561, 012021. [CrossRef]

76. Zhu, X.; El Fakhri, G. Proton therapy verification with PET imaging. Theranostics 2013, 3, 731-740. [CrossRef] [PubMed]

77. Freeman, T. Online MR imaging verifies proton beam range. Physicsworld. Available online: https://physicsworld.com/a/ online-mr-imaging-verifies-proton-beam-range/ (accessed on 6 December 2021).

78. Parodi, K.; Paganetti, H.; Cascio, E.; Flanz, J.B.; Bonab, A.A.; Alpert, N.M.; Lohmann, K.; Bortfeld, T. PET/CT imaging for treatment verification after proton therapy: A study with plastic phantoms and metallic implants. Med. Phys. 2007, 34, 419-435. [CrossRef]

79. Guan, F.; Bronk, L.; Titt, U.; Lin, S.H.; Mirkovic, D.; Kerr, M.D.; Zhu, X.R.; Dinh, J.; Sobieski, M.; Stephan, C.; et al. Spatial mapping of the biologic effectiveness of scanned particle beams: Towards biologically optimized particle therapy. Sci. Rep. 2015, 5, 9850 [CrossRef] [PubMed]

80. Chaudhary, P.; Marshall, T.I.; Perozziello, F.M.; Manti, L.; Currell, F.J.; Hanton, F.; McMahon, S.J.; Kavanagh, J.N.; Cirrone, G.A.P.; Romano, F.; et al. Relative biological effectiveness variation along monoenergetic and modulated Bragg peaks of a 62-MeV therapeutic proton beam: A preclinical assessment. Int. J. Radiat. Oncol. Biol. Phys. 2014, 90, 27-35. [CrossRef]

81. Rørvik, E.; Thörnqvist, S.; Stokkevåg, C.; Dahle, T.; Fjæra, L.; Ytre-Hauge, K. A phenomenological biological dose model for proton therapy based on linear energy transfer spectra. Med. Phys. 2017, 44, 2586-2594. [CrossRef]

82. Grün, R.; Friedrich, T.; Krämer, M.; Scholz, M. Systematics of relative biological effectiveness measurements for proton radiation along the spread out Bragg peak: Experimental validation of the local effect model. Phys. Med. Biol. 2017, 62, 890-908. [CrossRef]

83. McNamara, A.; Schuemann, J.; Paganetti, H. SU-F-BRD-13: A phenomenological relative biological effectiveness (RBE) model for proton therapy based on all published in vitro cell survival data. Med. Phys. 2015, 42, 3528. [CrossRef]

84. Ma, D.; Bronk, L.; Kerr, M.; Sobieski, M.; Chen, M.; Geng, C.; Yiu, J.; Wang, X.; Sahoo, N.; Cao, W.; et al. Exploring the advantages of intensity-modulated proton therapy: Experimental validation of biological effects using two different beam intensity-modulation patterns. Sci. Rep. 2020, 10, 3199. [CrossRef]

85. Michaelidesová, A.; Vachelová, J.; Puchalska, M.; Brabcová, K.P.; Vondráček, V.; Sihver, L.; Davídková, M. Relative bio-logical effectiveness in a proton spread-out Bragg peak formed by pencil beam scanning mode. Australas Phys. Eng. Sci. Med. 2017, 40, 359-368. [CrossRef]

86. Underwood, T.; Paganetti, H. Variable proton relative biological effectiveness: How do we move forward? Int. J. Radiat. Oncol. Biol. Phys. 2016, 95, 56-58. [CrossRef]

87. Wedenberg, M.; Beltran, C.; Mairani, A.; Alber, M. Advanced Treatment Planning. Med. Phys. 2018, 45, e1011-e1023. [CrossRef] [PubMed]

88. Stewart, R.D.; Carlson, D.J.; Butkus, M.P.; Hawkins, R.; Friedrich, T.; Scholz, M. A comparison of mechanism-inspired models for particle relative biological effectiveness (RBE). Med. Phys. 2018, 45, e925-e952. [CrossRef] [PubMed] 
89. Liu, Y.; Patel, S.A.; Jani, A.B.; Gillespie, T.W.; Patel, P.R.; Godette, K.D.; Hershatter, B.W.; Shelton, J.W.; McDonald, M.W. Overall survival after treatment of localized prostate cancer with proton beam therapy, external-beam photon therapy, or brachy-therapy. Clin. Genitourin. Cancer 2020, 19, 255-266. [CrossRef]

90. Tang, Q.; Zhao, F.; Yu, X.; Wu, L.; Lu, Z.; Yan, S. The role of radioprotective spacers in clinical practice: A review. Quant. Imaging Med. Surg. 2018, 8, 514-524. [CrossRef]

91. Chung, H.; Polf, J.; Badiyan, S.; Biagioli, M.; Fernandez, D.; Latifi, K.; Wilder, R.; Mehta, M.; Chuong, M. Rectal dose to prostate cancer patients treated with proton therapy with or without rectal spacer. J. Appl. Clin. Med. Phys. 2016, 18, 32-39. [CrossRef]

92. Polamraju, P.; Bagley, A.F.; Williamson, T.; Zhu, X.R.; Frank, S.J. Hydrogel spacer reduces rectal dose during proton therapy for prostate cancer: A dosimetric analysis. Int. J. Part. Ther. 2019, 5, 23-31. [CrossRef] [PubMed]

93. Dinh, T.-K.T.; Lee, H.J.; Macomber, M.W.; Apisarnthanarax, S.; Zeng, J.; Laramore, G.E.; Rengan, R.; Russell, K.J.; Chen, J.J.; Ellis, W.J.; et al. Rectal hydrogel spacer improves late gastrointestinal toxicity compared to rectal balloon immobilization after proton beam radiation therapy for localized prostate cancer: A retrospective observational study. Int. J. Radiat. Oncol. 2020, 108, 635-643. [CrossRef] [PubMed]

94. Murray, L.; Henry, A.; Hoskin, P.; Siebert, F.-A.; Venselaar, J. Second primary cancers after radiation for prostate cancer: A review of data from planning studies. Radiat. Oncol. 2013, 8, 172. [CrossRef]

95. Yoon, M.; Ahn, S.H.; Kim, J.; Shin, D.H.; Park, S.Y.; Lee, S.B.; Shin, K.H.; Cho, K.H. Radiation-induced cancers from modern radiotherapy techniques: Intensity-modulated radiotherapy versus proton therapy. Int. J. Radiat. Oncol. 2010, 77, 1477-1485. [CrossRef]

96. Weber, D.C.; Wang, H.; Cozzi, L.; Dipasquale, G.; Khan, H.G.; Ratib, O.; Rouzaud, M.; Vees, H.; Zaidi, H.; Miralbell, R. RapidArc, intensity modulated photon and proton techniques for recurrent prostate cancer in previously irradiated patients: A treatment planning comparison study. Radiat. Oncol. 2009, 4, 34. [CrossRef] [PubMed]

97. Peeters, A.; Grutters, J.; Pijls-Johannesma, M.; Reimoser, S.; De Ruysscher, D.; Severens, J.L.; Joore, M.; Lambin, P. How costly is particle therapy? Cost analysis of external beam radiotherapy with carbon-ions, protons and photons. Radiother. Oncol. 2010, 95, 45-53. [CrossRef] [PubMed]

98. Verma, V.; Mishra, M.V.; Mehta, M.P. A systematic review of the cost and cost-effectiveness studies of proton radiotherapy. Cancer 2016, 122, 1483-1501. [CrossRef] [PubMed]

99. Schippers, J.M.; Lomax, A.J. Emerging technologies in proton therapy. Acta Oncol. 2011, 50, 838-850. [CrossRef]

100. Schippers, M. New developments in cyclotrons and gantries for proton therapy. Verh. Der Dtsch. Phys. Ges. $2019,50,1$.

101. Lee, W.R. Prostate cancer and the hypofractionation hypothesis. J. Clin. Oncol. 2013, 31, 3849-3851. [CrossRef]

102. Tree, A.C.; Alexander, E.J.; Van As, N.J.; Dearnaley, D.P.; Khoo, V. Biological dose escalation and hypofractionation: What is there to be gained and how will it best be done? Clin. Oncol. 2013, 25, 483-498. [CrossRef]

103. Kim, Y.-J.; Cho, K.H.; Pyo, H.R.; Lee, K.H.; Moon, S.H.; Kim, T.H.; Shin, K.H.; Kim, J.-Y.; Lee, S.B.; Nam, B.H. A phase II study of hypofractionated proton therapy for prostate cancer. Acta Oncol. 2013, 52, 477-485. [CrossRef]

104. Cohilis, P.; Jongen, Y. Some factors influencing the cost of a hospital based proton therapy centre. Strahlenther. Onkol. 1999, 175, 102-104. [CrossRef]

105. Bolsi, A.; Lomax, A.J.; Pedroni, E.; Goitein, G.; Hug, E. Experiences at the Paul Scherrer Institute with a remote patient positioning procedure for high-throughput proton radiation therapy. Int. J. Radiat. Oncol. 2008, 71, 1581-1590. [CrossRef] [PubMed]

106. Fava, G.; Widesott, L.; Fellin, F.; Amichetti, M.; Viesi, V.; Lomax, A.J.; Lederer, L.; Hug, E.B.; Fiorino, C.; Salvadori, G.; et al. In-gantry or remote patient positioning? Monte Carlo simulations for proton therapy centers of different sizes. Radiother. Oncol. 2012, 103, 18-24. [CrossRef] [PubMed] 